\title{
Apresentação do Dossiê
}

\section{Interfaces da Educação Inclusiva, Saúde e Tecnologias Digitais}

O Programa Stricto Sensu em Educação, da Universidade Metodista de São Paulo, apresenta o Dossiê sobre Interfaces da Educação Inclusiva, Saúde e Tecnologias Digitais, que mantém seu compromisso de colaborar com a promoção e ampliação da análise e discussão de temas fundamentais para a Educação.

A finalidade da Revista Educação \& Linguagem, comprometida com a pesquisa acadêmica, é contribuir para a divulgação de trabalhos relacionados às políticas e práticas sociais da Educação em suas múltiplas linguagens. Para isso, conta com a contribuição de pesquisadores brasileiros de várias regiões do país e também autores internacionais.

Esta edição, coordenada pelo Prof. Dr. Claudio Fernando André, docente pesquisador do Programa de Pós-Graduação em Educação da Universidade Metodista de São Paulo, traz o debate a respeito de temas importantes neste momento em que discutimos, na academia e na sociedade, questões relativas à educação inclusiva e saúde, considerando também a utilização crescente das tecnologias digitais em seus diferentes níveis, modalidades, formatos e atividades.

Contamos com a colaboração de professores e alunos de universidades que, com a habitual competência e dedicação acadêmicas, se dedicam à reflexão e ao debate dos assuntos destacados, importantes para garantir a qualidade do processo de ensino e aprendizagem que devem pautar a formação docente.

Da Universidade Feevale/RS, recebemos os trabalhos: a) VISNode - uma ferramenta gamificada para o aprendizado de processamento digital de imagens; b) O uso de simuladores no auxílio 
do ensino-aprendizagem na Enfermagem; c) Impressão 3D aplicada ao ensino de ciências básicas da saúde: onde estamos e onde queremos chegar e; d) Metodologias ativas associadas ao uso de tecnologias no âmbito educacional: produções científicas de enfermagem, uma revisão integrativa de literatura.

O primeiro trabalho, dos pesquisadores Jonata Daniel Becker, Nicolas Pohren e Marta Rosecler Bez, tem como objetivo apresentar o desenvolvimento do módulo gamificado para a ferramenta VISNode, visando o suporte ao aprendizado na área de processamento digital de imagens (PDI). O segundo, dos pesquisadores Gabriela Antoneli, Michele Antunes, Paulo Ricardo Muniz Barros, Sandro Rigo, Marie Jane Soares Carvalho, Marta Rosecler Bez, verifica a perspectiva dos acadêmicos do curso de enfermagem acerca do uso de simuladores no auxílio do ensino-aprendizagem. $\mathrm{O}$ terceiro, dos pesquisadores Amanda Dalla'Cort Chaves, João Miguel Menezes Dutra e Cláudio Felipe Kolling da Rocha, tem como objetivo demonstrar como novas tecnologias enquanto recursos educacionais impressos em 3D (REs 3D) podem auxiliar na sua compreensão na formação básica de profissionais da saúde. O último trabalho, dos pesquisadores Lívia Biasuz Machado, Igor de Oliveira Lopes, Rithiely Allana Bárbar, Kátia Fernanda Souza de Souza, Isabel Cristina Wingert e Júnior Felipe Luft, analisa a possibilidade de aliar modelos como metodologias ativas e tecnologias ao currículo educacional de enfermagem, que pode facilitar o processo de ensino aprendizagem de discentes. Trata-se de uma revisão integrativa de literatura, nos bancos de dados SCIELO e LILACS, de 2013 a 2017.

No artigo "Os desafios da formação do professor para educação de surdos", a autora Leliane Aparecida Castro Rocha, da Universidade Metodista de São Paulo, faz uma discussão sobre a formação de professores que atuam com a educação inclusiva para surdos, na busca da inclusão escolar com qualidade. O artigo "A educação dos alunos com deficiência auditiva no Brasill, dos autores Claudio Fernando André e Maria Cristina Teixeira, também da Universidade Metodista, tem a finalidade de sistematizar e analisar 
o desenvolvimento da educação das pessoas com deficiência auditiva no Brasil.

O artigo "Educação inclusiva: os avanços legislativos nos 30 anos da Constituição Federal de 1988”, de autoria de Flávia Piva Almeida Leite e Adriano Fernando Segantin, da UNESP, tem como finalidade analisar os avanços legislativos ocorridos após a vigência da Constituição Federal de 1988, notadamente no tocante à realização do direito fundamental à educação da pessoa com deficiência no Direito brasileiro.

$\mathrm{O}$ artigo "Modelo conceptual y tecnológico para apoyo a niños con discalculia", dos pesquisadores María Alejandra Hurtado Parra e Néstor Darío Duque-Méndez, da Universidade Nacional da Colômbia, apresenta um modelo conceitual e um ambiente informatizado educacional ancorado em atividades educacionais voltadas para crianças com dificuldades de aprendizagem relacionadas à matemática, o que permite a detecção precoce e também apoia estratégias específicas para o nível de dificuldade encontrado, permitindo o monitoramento da evolução de cada aluno.

O artigo "Modelo sistemático para utilização dos recursos e ferramentas da plataforma Moodle: uma proposta para mediação da aprendizagem no ensino superior", de autoria dos pesquisadores Natana Lopes Pereira, Prof. Dr. Fernando José Spanhol e Prof. Dr. Giovani Mendonça Lunardi, da Universidade Federal de Santa Catarina, apresenta um roteiro às reflexões sobre a construção e conversão de conhecimento, considerando que, a partir de um modelo inicial, pode-se proporcionar maior efetividade nos ambientes virtuais de ensino e aprendizagem, por meio de quatro modos denominados de modelo SECI - Socialização, Externalização, Combinação, Internalização.

Pela colaboração, imprescindível e generosa, de todos(as) os(as) autores(as), meu eterno agradecimento.

Boa leitura!

Prof. Dr. Claudio Fernando André 